that year the Department of Education and Science projections indicate around 53000 girls in England and Wales with five $\mathrm{O}$ levels and two A levels. At present figures about one quarter of this group will enter nursing. The shortfall of new entrants is obvious-hence the need to put the plug in the bath and reduce the losses by wastage and for programmes to encourage former nurses to return to nursing. In addition, an effort must be made to recruit from the older age groups, notably those women who have had their families. And at present $10 \%$ of entrants to nursing are men, and this number might also be increased.

The commission claims that all these steps may help increase manpower and that if the present arrangements continue the problems will get even worse. Nevertheless, the question remains: "Who will nurse the patients?"

The cost benefit implications are equally complex. On the benefit side the commission was convinced that its proposals will produce high calibre nurses and that as a result the care of patients would be enhanced, but research is needed to cost such benefits. Detailed analysis shows how many of the costs of the present system are hidden. Making certain assumptions regarding some of these hidden costs, the commission came up with figures for the total costs to produce a qualified nurse. These put the cost in present schools of nursing at $£ 8750$, in the degree sector at $£ 17340$, and with the proposed diploma at $£ 10251$. Much of the increased cost of the degree/diploma sector is due to the decrease in the service provided by these students. Further costs would result from courses to convert the present State Enrolled Nurse level nurse to "Registered" level.

Inevitably, therefore, the cost of implementing the proposals will be greater than those costs presently incurred. Where this money is to come from is of crucial importance -health departments or the Department of Education and Science? Whichever is chosen the source is the Treasury purse and someone has to put the money in. Clearly, if the better preparation results in better patient care, fewer complications, quicker discharge, and reduced mortality, then the cost benefit analysis may look more favourable.

Whatever happens to the proposals-and they must not join those of Wood, ${ }^{2}$ Platt, ${ }^{3}$ and Briggs ${ }^{4}$ in gathering dustthe message remains: something has to be done. The body charged by parliament with this task is the United Kingdom Central Council for Nursing, Midwifery, and Health Visiting. ${ }^{5}$ It has its own group_-"Project 2000"-addressing the same question. No doubt the Royal College of Nursing Commission's report will provide a welcome input to its considerations.

Professor of Nursing Education,

C M CHAPMAN

University of Wales College of Medicine,

Cardiff CF4 4XN

1 Annexe of Research Studies for Commission of Nursing Education. The education of nurses: a new dispensation. London: Royal College of Nursing, 1985. (Chairman Dr Henry Judge.) dispensation. London: Royal College of Nursing, 1985. (Chairman Dr Henry Judge.)
nterdepartmental Working Party on the Recruitment and Training of Nurses. Report of the working Interdepartmental Working Party on the Recruitment and Traini
party. London: HMSO, 1947. (Chairman Sir Robert Wood.)

3 Special Committee on Nurse Education. A reform of nursing education. First report. London: Royal College of Nursing, 1964. (Chairman Sir Harry Platt.)

4 Committee on Nursing. Report.London: HMSO, 1972. (Chairman Sir Asa Briggs.)

5 Nurses, Midwives and Health Visitors Act 1979. London: HMSO, 1979: paragraph 2.

\section{Management of menorrhagia}

Menorrhagia is a common gynaecological problem and management depends on the underlying cause. This article is concerned mainly with patients who have no serious pelvic or general disease, although women with small fibroids or minimal endometriosis may be treated similarly.

The best treatment for young women, especially those whose families are incomplete, is usually a suitable oral contraceptive. But for older women, especially those whose family is complete, alternative treatment, including hysterectomy, should be considered. Hysterectomy is said to cause sexual difficulties and psychological problems ${ }^{1-3}$ but in an extensive review Meikle found no firm evidence to support such claims, ${ }^{4}$ and a subsequent prospective longitudinal study showed that among patients treated with hysterectomy were a subgroup with longstanding preoperative psychiatric morbidity. ${ }^{5}$ These patients are still benefited by hysterectomy but are more likely to develop psychological problems than the average patient. In another prospective study patients reported an improvement in mood and vigour and unimpaired sexual activity. ${ }^{6}$

A decision on surgical or conservative treatment must take account of the patient's own wishes, her age, and the severity of her symptoms. Symptoms of recent origin may be due to stress and may remit spontaneously, ${ }^{7}$ while patients approaching the average age of the menopause (51) may also avoid surgery. Those less suited to conservative treatment include younger women with severe bleeding, appreciable enlargement of the uterus, and anaemia, and those in whom bulky uterine curettings are found-especially if these are associated with endometrial hyperplasia. ${ }^{8}$ Uterine curettage should be regarded as a diagnostic procedure, primarily for those women who are having irregular bleeding, for there is no evidence that it is helpful by itself for menorrhagia. ${ }^{9}$ Laser photoevaporation of the endometrium appears to have no advantages over hysterectomy. ${ }^{10}$

A bewildering choice of drugs have been advocated for the conservative treatment of menorrhagia. These include hormones, antioestrogens, prostaglandin inhibitors, antifibrinolytics, drugs to stabilise capillary vessel walls, and ergot preparations. Treatment with iron also has a place, to correct or prevent anaemia. Apart from oral contraceptives the most widely used hormone is norethisterone, a synthetic progestin. It is most useful in women who are found to have a non-secretory endometrium, especially those with metropathia haemorrhagica. The latter is often self limiting and a three month cyclical course of norethisterone may be all that is required. Norethisterone may also be effective in ovulatory menorrhagia, including the emergency treatment of menstrual haemorrhage. Disadvantages to its use include an increase in pelvic vascularity and uterine size (making subsequent surgery more hazardous), an effect on the histology of the endometrium, and, in some cases, worsening of dysmenorrhoea. ${ }^{11}$ Thus it is best reserved for patients with proved anovulatory bleeding.

Prostaglandin synthetase inhibitors are effective in about $80 \%$ of patients with moderately heavy periods. ${ }^{12}$ They are also helpful for women with intrauterine contraceptive devices. ${ }^{13-15}$ These drugs have the advantage that they lessen menstrual pain and need be taken only during menstruation. Many prostaglandin synthetase inhibitors are effective, but my own experience is confined to mefenamic acid $250 \mathrm{mg}$ and flurbiprofen $50 \mathrm{mg}$ (although flurbiprofen does not have a product licence for use in menorrhagia). For both drugs the recommended treatment is two tablets as soon as the loss becomes heavy, then one tablet as required for as long as necessary. Heavy loss rarely exceeds three days and if it does the patient is probably unsuited for this form of treatment. On this dose regimen side effects are rare.

Antifibrinolytics are an alternative to prostaglandin syn- 
thetase inhibitors but tend to cause more side effects. Tranexamic acid is probably the best; 1.0 or $1.5 \mathrm{~g}$ is given six hourly during heavy bleeding. ${ }^{131617}$ It is especially suitable for patients with bleeding disorders. Aminocaproic acid is less convenient to take, less effective, and more likely to cause side effects. ${ }^{10} 17-20$

Ethamsylate has a direct action on capillaries, and several workers have shown that it reduces menstrual loss. ${ }^{21}$ Kasonde and Bonnar, however, found it to be of no value in women with haemorrhage associated with intrauterine contraceptive devices. ${ }^{22}$

Danazol depresses the secretion of gonadotrophins and sex steroids but possesses some anabolic and weakly androgenic properties. In a dose of $200 \mathrm{mg}$ daily it reduces menstrual loss and raises haemoglobin concentrations. Patients may be treated for three months and benefit may continue for a further three months. ${ }^{23}$ Danazol may, however, potentiate anticoagulants such as warfarin ${ }^{24}$ and cause gain in weight and possibly hirsutism. Its use should, therefore, probably be confined to women with severe symptoms who fail to respond to other treatments and are unwilling to undergo surgery.

Ergot alkaloids are of no value in treating menorrhagia, ${ }^{10}$ and irradiation —once a legitimate alternative to surgery-is also now obsolete. (Side effects include a slightly increased risk of developing malignant disease, ${ }^{25}$ and symptoms due to lack of oestrogen.)

Prostaglandin synthetase inhibitors, tranexamic acid, and ethamsylate have proved to be the most useful drugs in the conservative management of menorrhagia (not due to intrauterine contraceptive devices), and further well designed comparative studies are needed to establish their relative merits.

Consultant Gynaecologist, Royal Hampshire County Hospital,

Winchester SO22 5DG

1 Richards DH. Depression after hysterectomy. Lancet 1973;ii:430-2.

2 Richards DH. A post hysterectomy syndrome. Lancet 1974; ii $983-5$.

3 Barker MG. Psychiatric illness after hysterectomy. Br Med F 1968;ii:91-5.

4 Meikle S. The psychological effects of hysterectomy. Canadian Psychological Reviews 1977;18: 128-41.

5 Gath D, Cooper P, Day A. Hysterectomy and psychiatric disorder: I. Levels of psychiatric morbidity before and after hysterectomy. Br $\mathcal{F}$ Psychiatry 1982;140:335-50.

6 Coppen A, Bishop M, Beard RJ, Barnard GJR, Collins WP. Hysterectomy, hormones, and behaviour. Lancet 1981;i:126-8.

behaviour. Lancet 1981;i:126-8.
Nilsson L, Rygo G. Treatment of menorrhagia with epsilon aminocaproic acid. Acta Obstet

Gynecol Scand 1965;44:467-73.
Nilsson L, Rygo G. Treatment

Carr C. Results of conservative treatment of dysfunctional uterine bleeding in the fifth decade of life. Fournal of Obstetrics and Gynaecology of the British Commonwealth 1966;73:828-31.

9 Nilsson L, Rybo G. Treatment of menorrhagia. Am 7 Obstet Gynecol 1971;110:713-20.

10 Goldrath MH, Fuller TA, Segal S. Laser photovaporization of endometrium for the treatment of menorrhagia. Am $\mathcal{F}$ Obstet Gynecol 1981;140:14-9.

1 Bishop P, di Almeida JCC. Treatment of menstrual disorders. BrMed f 1960;ii: 1103-5.

12 Elder MG. Prostaglandins and menstrual disorders. Br Med $\mathcal{J}$ 1983;287:703-4

13 Ylikorkala $\mathrm{O}$, Viinikka $\mathrm{L}$. Comparison between antifibrinolytic and antiprostaglandin treatment in reduction of increased menstrual loss associated with IUCD's. Br f Obstet Gynaecol 1983;90:
$78-83$.

14 Ylikorkala O, Kaupilla A, Sitjander M. Antiprostaglandin therapy in prevention of side effects of intrauterine contraceptive devices. Lancet 1978;ii:393-4.

15 Hayne PJ, Flint APF, Hodgson H, et al. Studies in menorrhagia. (a) Mefenamic acid (b) endometrial prostaglandin concentrations. Int f Gynaecol Obstet 1980;17:567-72.

metrial prostaglandin concentrations. Int Gynaecol Obstet $1980 ; 17: 567-72$.
Nilsson L, Rybo G. Treatment of menorrhagia with antifibrinolytic agent, tranexamic acid. Acta Obstet Gynecol Scand 1967;46:572-80.
.

17 Bonnar RJ, Gillebaud J, Kasonde JM, Sheppard BL. Clinical applications of fibrinolytic inhibition in gynaecology. F Clin Pathol 1980;33:55-9.

18 Nilsson L, Bjorkman S. Experiences with epsilon aminocaproic acid in the treatment of profuse menorrhagia. Acta Med Scand 1965;177:445-57.

19 Vermylen J, Verhaegen-Dechereq ML, Verstratte M, Fierans FA. Double blind study of the effect of tranexamic acid in essential menorrhagia. Thrombosis et Diathesis Haemorrhagica 1968 20:583-7.

20 Kasonde JM, Bonnar RJ. Epsilon aminocaproic acid and menstrual loss in women with intrauterine contraceptive devices. Br Med J 1975;iv: 17-9.

21 Harrison RF, Campbell S. A double blind trial of ethamsylate in the treatment of primary and intrauterine contraceptive devices menorrhagia. Lancet 1976;ii:283-5.

2 Kasonde JM, Bonnar RJ. Effects of ethamsylate and epsilon aminocaproic acid in menstrual blood loss in women with intrauterine contraceptive device. Br Med f 1975; iv:21-2.

23 Chimbira TH, Anderson ABM, Cope E, Turnbull AC. Reduction of menstrual blood loss by danazol in unexplained menorrhagia: lack of effect of placebo. Br f Obstet Gynaecol 1980;87.
. $1152-8$.

24 Small M, Peterkin M, Lowe DGO, et al. Danazol and oral anticoagulants. Scott Med F 1982;27: $331-2$

25 Doll $\mathrm{R}$, Smith $\mathrm{R}$. Long term effects of $\mathrm{x}$ irradiation in patients treated for metropathia haemorrhagica. Br f Radiol 1968;4:362-8

\section{Haemolysis in childhood}

The causes and frequency of haemolysis in childhood vary according to age. In the neonatal period haemolysis is invariable; it may be physiological or pathological. Physiological haemolysis-destruction of red cells-is never more intense than in the haemolysis of fetal red cells just after birth, almost halving the initial circulating haemoglobin concentration by the time of resumption of erythropoiesis at about seven weeks after full term delivery. "Physiological" jaundice, resulting from this haemoglobin catabolism, is exaggerated to hyperbilirubinaemia in term babies by fetal and neonatal diseases, maternal disorders, or a combination of these. ${ }^{1}$ When there is a history of maternal smoking ${ }^{2}$ or administration of oxytocin the effects may be mediated through impairments in the baby's red cell deformability, though the effects of oxytocin are controversial. ${ }^{3}$ Preterm infants are more at risk of haemolytic jaundice, ${ }^{1}$ not only because of hepatic functional immaturity but also because of their greater dependence at birth on mainly fetal red cells, whose viability is reduced for both functional and metabolic reasons. ${ }^{4}$

Pathological haemolysis-haemolytic anaemia-is never more common than in the neonatal period. ${ }^{5}$ Underlying this may be intrinsic abnormalities of the red cell's membrane such as hereditary spherocytosis, enzymopathies such as deficiency of glucose-6-phosphate dehydrogenase, or, rarely, even haemoglobinopathies such as homozygous sickle cell disease (though since this is a $\beta$ globin chain abnormality it usually causes little haemolysis before the second month of life). ${ }^{6}$ Such haematological diagnoses of inherited red cell abnormalities may be made more confidently from the age of 3 months.

In white people, however, the most common cause of neonatal haemolytic anaemia is still fetomaternal isoimmunisation. Antirhesus ( $R h) \mathrm{D}$ prophylaxis has reduced fetomaternal immunisation by almost $90 \%$; in 1968 there were 750 stillbirths and infant deaths from $\mathrm{Rh}(\mathrm{D})$ haemolytic disease of the newborn, compared with 123 10 years later. Failure of anti-D prophylaxis may result from antenatal immunisation, inadvertent omission, or inadequate dosage. ${ }^{7}$ Antenatal anti-D prophylaxis may reduce maternal immunisation even further though the cost effectiveness of this remains controversial. ${ }^{8}$ With the success of anti-D prophylaxis, other antibodies are now becoming relatively more important. ${ }^{9}$ Any antibody which crosses the placenta may cause haemolytic disease of the newborn. As yet no other prophylaxis against maternal immunisation is available. After birth, phototherapy, transfusion of red cells, and exchange transfusion are still the mainstays of treatment of haemolytic disease of the newborn. ${ }^{10}$

In older children acute autoimmune haemolytic anaemia causes haemoglobinuria and life threatening anaemia; acute autoimmune haemolytic anaemia is uncommon and so is unlikely to be seen more than a few times by any one haematologist or paediatrician, and their experience of treatment must be limited. The recent review by Sokol et al of 42 cases studied over the past 23 years at the Sheffield Regional Blood Transfusion Service, therefore, contains useful guidance in investigation, management, and prognosis of these rare but acutely worrying problems. ${ }^{11}$ Two thirds of the patients were children under 5 years old in whom the acute haemolysis usually occurred after trivial infections and was short lived. They recommend that steroids should be reserved for children suffering from persistent and severe haemolytic anaemia after two or three 